\title{
Board Games on Emotional Competences for School-Age Children
}

\author{
Linda Dell'Angela, MSc, ${ }^{1,2}$ Alexandra Zaharia, MSc, ${ }^{1,3,4}$ Adam Lobel, PhD, ${ }^{1}$ \\ Ornella Vico Begara, MSc, ${ }^{2}$ David Sander, Prof. PhD, ${ }^{1,2}$ and Andrea C. Samson, Prof. PhD ${ }^{1,3,4}$
}

\begin{abstract}
Objective: Emotional competences (EC) are important for social and academic outcomes and positive life trajectories. Due to their social setting and tendency to stimulate intrinsic motivation, board games may constitute efficient learning tools for promoting socioemotional development in children. The current project therefore aimed at developing and testing three theory-driven board games explicitly targeting EC. First, we explored the quality of these EC games in terms of game experience, compared to off-the-shelf games (without an EC focus). Second, we tested whether targeted EC were linked to game experience in the EC games by measuring associations between children's trait EC and subjective effort and difficulty during gameplay.

Materials and Methods: Children $(N=177)$ aged $8-12$ years old were randomly assigned to a four-session protocol that comprised EC board games (experimental group) or off-the-shelf board games (control group). At baseline, participants' trait EC (emotion recognition, differentiation, and cognitive reappraisal) were assessed, while game experience (e.g., positive and negative affect, flow and immersion, difficulty, and effort) was assessed after each game.

Results: Both groups perceived the games they played as positive and playable. Furthermore, regression analyses showed that higher trait EC was linked to lower self-reported effort and difficulty in two of the EC board games focusing on emotion recognition and differentiation.

Conclusion: The present study shows that the board games on EC designed for children seem to elicit game experiences comparable to off-the-shelf games. Moreover, children's trait EC were linked to subjective game experience in two of the three games. Future interventions should examine the potential of the novel games to promote EC.
\end{abstract}

Keywords: Emotional competences, Emotion recognition, Emotion differentiation, Cognitive reappraisal, Play, Board games

\section{Introduction}

$\mathbf{E}$ MOTIONS AND EMOTIONAL competences (EC) play a crucial role at school, impacting social and academic outcomes. $^{1,2}$ For instance, experiencing positive emotions can stimulate learning and skill acquisition, promote exploration, optimism, and success, ${ }^{3}$ and enhance academic grades through higher intrinsic motivation and self-regulated learning. ${ }^{4}$ Positive emotions can also diminish harmful effects of stress and pressure on learning. ${ }^{5}$ In contrast, negative emotions (e.g., frustration, disappointment, hopelessness, and boredom) can negatively impact motivation and learning processes. ${ }^{6} \mathrm{EC}$ are integral to emotional experience because they characterize how individuals experience, express, identify, understand, use, and regulate their own and others' emotions in an adaptive way. ${ }^{7,8}$

To assure optimal learning conditions, schools thus benefit from teaching children to recognize, differentiate, and adaptively regulate their emotions. Moreover, EC have a positive impact on learning by enhancing teacher-student relationships, social competences, and school-related beliefs. ${ }^{5,9}$ Since many mental disorders have been linked to

\footnotetext{
${ }^{1}$ Swiss Center for Affective Sciences, Campus Biotech, University of Geneva, Geneva, Switzerland.

${ }^{2}$ Faculty of Psychology and Educational Sciences, University of Geneva, Geneva, Switzerland.

${ }^{3}$ Faculty of Psychology, Swiss Distance University Institute, Brig, Switzerland.

${ }^{4}$ Institute of Special Education, University of Fribourg, Fribourg, Switzerland.
} 
poor EC, ${ }^{10}$ promoting EC in schools could represent one potential protective factor against the development of psychopathologies. Given the benefits of including EC into the academic curriculum, an increasing number of socioemotional learning (SEL) programs have been developed for the school context. ${ }^{11,12}$ Meta-analyses evaluating long-term and large-scale benefits have shown not only social and emotional but also academic gains. ${ }^{2,13,14}$

\section{Emotional competences}

The current article focuses on emotion recognition, differentiation, and adaptive emotion regulation (i.e., cognitive reappraisal) as signature EC that have been linked to adaptive functioning and positive long-term outcomes. ${ }^{3,9,10,15-21}$

Emotion recognition is the ability to accurately recognize other peoples' emotions based on nonverbal facial, vocal, and bodily cues. ${ }^{22}$ It supports other emotional and social competences, ${ }^{23,24}$ including the regulation of social interactions; it helps people to infer others' affective states, to predict their intentions, to understand behaviors, and to adapt one's own emotions. ${ }^{7,25}$

Emotion differentiation (or granularity) is the ability to describe one's own affective experiences in differentiated and specific emotion labels. ${ }^{17,18,26-28}$ An individual with high differentiation capabilities uses different emotion labels for various subjective feelings, whereas someone with low differentiation capabilities uses emotion words interchangeably for a general pleasant or unpleasant state. Labeling a subjective feeling activates emotion-specific knowledge about its causes, appraisal patterns, specific contexts, and possible consequences. ${ }^{16}$ Therefore, accurately labeling emotions helps to adaptively respond to emotion-eliciting situations and to choose appropriate emotion regulation strategies, prevents from misattribution errors, ${ }^{29}$ and contributes to adaptive functioning. ${ }^{15,18,30,31}$

Emotion regulation characterizes the processes through which people influence the emotions they have, when they have them, and how they experience and express them. ${ }^{32}$ The frequent use of adaptive strategies is positively related to health, relational, academic, and professional success. ${ }^{33}$ One of the most studied adaptive strategies is cognitive reappraisal, which refers to reinterpreting a situation in a different light to change its emotional impact. ${ }^{33-36}$ Cognitive reappraisal has been shown to be adaptive and highly effective in downregulating the subjective experience and psychophysiological (e.g., cardiovascular and electrodermal) correlates of emotions. $^{35,36}$

Research has shown that these EC are closely intertwined, such that emotion differentiation is related to emotion recognition in others, ${ }^{37}$ and that emotion differentiation is a necessary precursor to adaptively regulate emotions. ${ }^{15,28,29}$ However, since they focus on specific domains and can be measured independently, we aimed to target these three EC with the EC games in the current study.

\section{Play and emotional competences}

Play in general, and games more specifically, have been considered as potential learning mechanisms throughout childhood. ${ }^{38-44}$ Games may foster learning of various concepts and competences, including EC, through several mechanisms: they provide active and experience-based learning opportunities, ${ }^{45}$ elicit longer sustained attention, ${ }^{46}$ facilitate understanding, ${ }^{47}$ provide immediate feedback, and give children a sense of control. ${ }^{4,48}$ The presence of peers encourages players to persist longer while facing challenges and to be more creative during problem-solving. ${ }^{41,49}$ Moreover, games trigger intrinsic motivation and positive emotions (e.g., amusement, fun, and pleasure). ${ }^{40,50}$

Games also show promising results when used as educational tools ${ }^{38,45,51-53}$ and may be promising in SEL programs to promote EC. ${ }^{39,41}$ Researchers identify three levels on which board games may promote SEL skills ${ }^{41}$ : on the skilllevel, children can practice a skill during game play. On the interactional level, children use the skill with each other. Finally, the mediated level further enhances learning with the help of facilitators (e.g., therapists and teachers). Interestingly, many educational games transmit knowledge in a question-answer manner. ${ }^{54}$ However, to sustain the development of a competence, the game mechanics must go beyond transmitting knowledge and favor the use and training of specific competences during game play.

\section{Present study}

Given the importance of promoting EC in children and the potential of board games to foster behavior change, the current project aimed at designing games that specifically target EC, that is, those that have EC as explicit topics as well as that EC have to be used and thus practiced during game play. A team of psychologists developed several prototypes, which were improved through play-testing sessions with children, researchers in affective sciences, and professional game designers. They resulted in the Recognition Game, the Differentiation Game, and the Reappraisal Game.

The present article reports first analyses of the EC board games experience. Therefore, we have tested on one hand, the game experience during play as reflected by children's reports, and, on the other hand, the way in which children's trait EC are linked to game experience while playing the games.

First, we compared the quality of the EC games to commercially available, off-the-shelf games using similar game mechanics, but with no explicit focus on emotion. The goal was to explore how the EC games would differ in terms of game experience from already published games. For this purpose, a questionnaire designed to test digital game experience (positive and negative emotions, immersion and flow, difficulty, and effort) in adults was adapted for children and board games.

Second, we examined whether children's EC traits would be linked to their game experience during EC board game play. Based on the assumption that the players' competences challenged in a game actually contribute to their game experience, ${ }^{55}$ we expected that the targeted EC are linked to difficulty and effort experienced during game play. Specifically, we hypothesized that children would rate the games easier and less effortful if they scored higher on emotion recognition and differentiation for the Recognition Game, on emotion differentiation and reappraisal for the Differentiation Game, and on reappraisal for the Reappraisal Game. Given that playing off-the-shelf board games might contribute to children's development and promote various cognitive, social, and EC, we also explored the associations between trait EC and game experience. 


\section{Methods}

\section{Participants}

Six public and private schools were recruited in Frenchspeaking Swiss cantons (Geneva and Vaud), resulting in 177 participants aged 8-12 years with varying socioeconomic backgrounds and 46 different nationalities. The study was approved by the Ethics Committee of the Faculty of Psychology and Educational Sciences at the University of Geneva, Switzerland. Parents' written informed consent and demographic information were obtained before children's participation. Three children were excluded due to insufficient language skills or previous participation in playing the games. This resulted in a sample of 174 participants (95 boys, 79 girls). For demographic information see Table 1.

\section{Design}

The games were tested in a program of four, 90-minute sessions. Children of the same school were randomly assigned to experimental or control playgroups of 9-10 children on average. In the first session, participants completed trait EC measures. In the three following sessions, children in the experimental condition played the three EC board games (one per session), while the control participants played three off-the-shelf games matched in terms of game mechanics, but without explicit emotional content. After each session, they reported their game experience. The order of the games was counterbalanced across groups. The groups did not differ in gender distribution $\left[\chi^{2}(1, N=174)=0.92\right.$, $P=0.338]$.

\section{Games}

The Recognition Game targets emotion expression and recognition. Each turn, a player expresses a sentence (e.g., "My mother forgot my birthday!") while conveying one of six emotions from a list (e.g., happy, sad, frustrated, and so on) to their group; the group determines the emotion which is being conveyed. Because the sentence and the emotion are selected at random, they could be congruent or not. Children in the control condition played Mimtoo, ${ }^{56}$ a pantomime game with two competing groups. Taking turns, a player of each group mimes as many sentences (subject and action) as possible to his group in a given time.

The Differentiation Game targets emotion differentiation and reappraisal. Players convey a distinct set of events to their group by referring to them with one emotion word. The more precise the emotional label, the better the group can identify the target event among similar distractors. Players also need to reappraise the event using other player's perspectives and be aware that different emotions can occur depending on the interpretation one gives to an event. Children in the control condition played Codenames, ${ }^{57}$ which has similar mechanics but no emotional contentplayers convey words instead of emotional events, using related terms instead of emotional words.

The Reappraisal Game is a cooperative story-telling game targeting cognitive reappraisal. Each player adds different elements from cards (e.g., princess and forest) to the story. Toward the end, "complications" eliciting negative emotions are introduced into the story; these complications have to be reappraised with a specific cognitive reappraisal strat- egy (e.g., reinterpretation, thinking about resources, and acceptance). ${ }^{36}$ This game was compared to Once Upon A Time (OUAT), ${ }^{58}$ a cooperative story-telling game without any mechanisms instigating negative twists in the narrative or reappraisal.

For more detailed information about the games, see Table 1 and Supplementary Data.

\section{Measures of trait emotional competences}

French versions of the questionnaires were administered individually on tablets.

Emotion recognition was assessed with the Geneva Emotion Recognition Test-Short (GERT-S), ${ }^{59,60}$ an ecological measure of multimodal emotion recognition. Fourteen emotions were displayed in 42 short videos of actors pronouncing nonwords. After each video, the 14 emotions are displayed on the screen and participants are asked to choose the emotion expressed by the actor. Cronbach's alpha was 0.76 , which is acceptable, but slightly below the value found in the validation articles.

Emotion differentiation was measured with a 7-item subscale of the Emotion Awareness Questionnaire (EAQ), which has previously been validated in children (e.g., "It is difficult to know whether I feel sad or angry or something else."). ${ }^{30,61}$ The subscale assesses self-reported emotional clarity on a 3-point scale. The Cronbach's alpha obtained in our sample $(\alpha=0.72)$ is acceptable and even slightly above the value from the validation article.

The habitual use of cognitive reappraisal was assessed with the reappraisal subscale (six items) of the Emotion Regulation Questionnaire (ERQ) (Seguin J, Emotion Regulation Questionnaire-French version, unpublished data). ${ }^{62,63}$ We used a 7-point scale version for children (e.g., "I control my emotions by changing the way I think about the situation I'm in'”). The Cronbach's alpha obtained in our sample $(\alpha=0.83)$ was good and corresponds to the ones found in the children version of the ERQ. ${ }^{63}$

\section{Game experience}

To our knowledge, no French questionnaire assessing board game experience in children is currently available. We therefore translated into French the Game Experience Questionnaire (GEQ), ${ }^{64}$ assessing digital game experience and originally validated in adults, and adapted it for children and board games (Board Game Experience Questionnaire, BGEQ; see Supplementary Data). The newly adapted questionnaire assesses positive and negative affect, flow and immersion, difficulty, and effort on a 5-point scale.

\section{Analyses}

First, each EC board game was compared with its control game on the BGEQ subscales. A separate one-way betweengroup MANOVA (multivariate analysis of variance) was run for each pair of games, with condition (experimental, control) as between-subjects factor and the five dimensions of the BGEQ (positive affect, negative affect, flow-immersion, difficulty, and effort) as dependent variables.

Second, multiple linear regression analyses were performed separately for each game, with the respective EC as predictors on difficulty and effort. Concretely, we tested the 


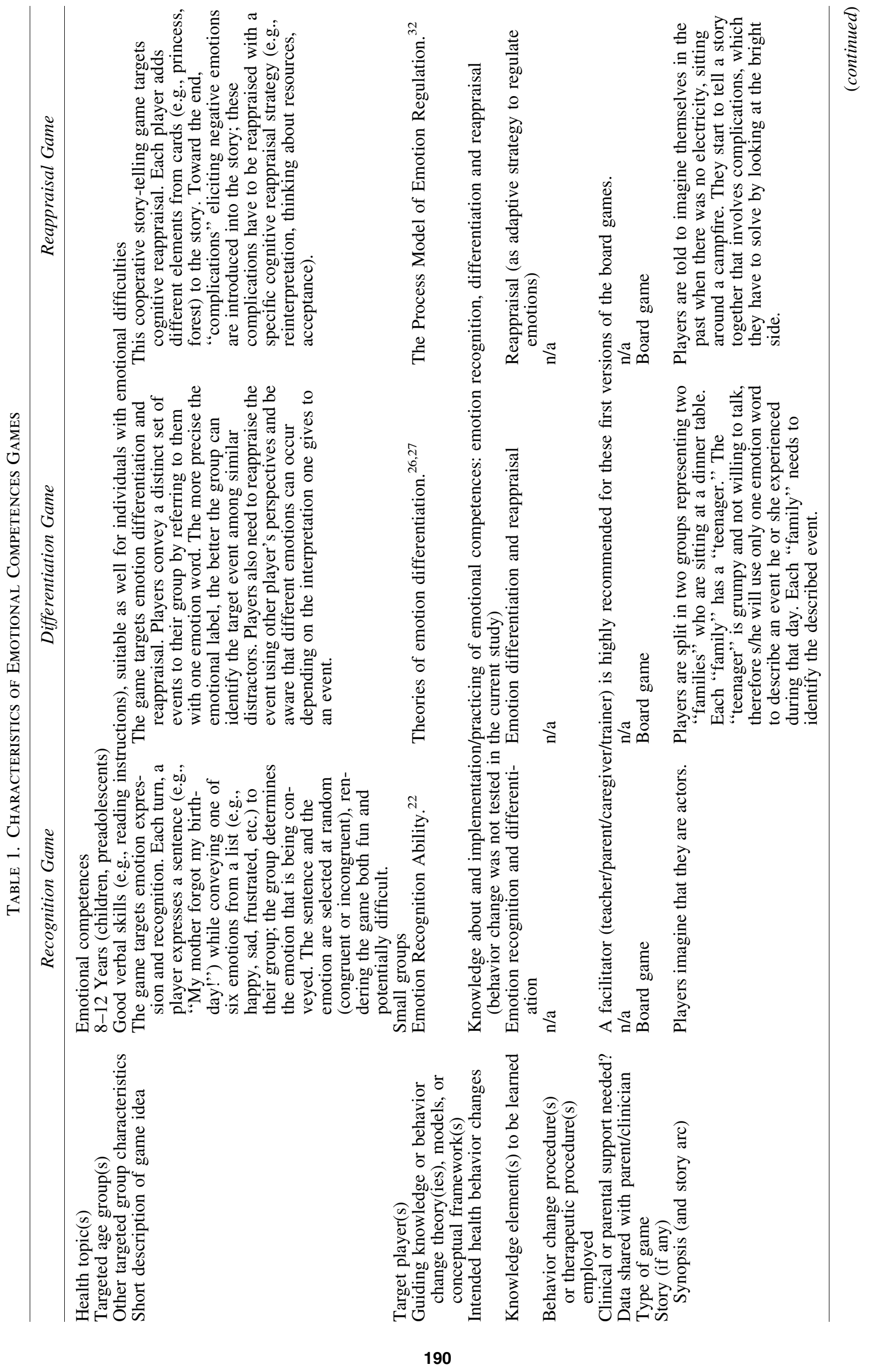




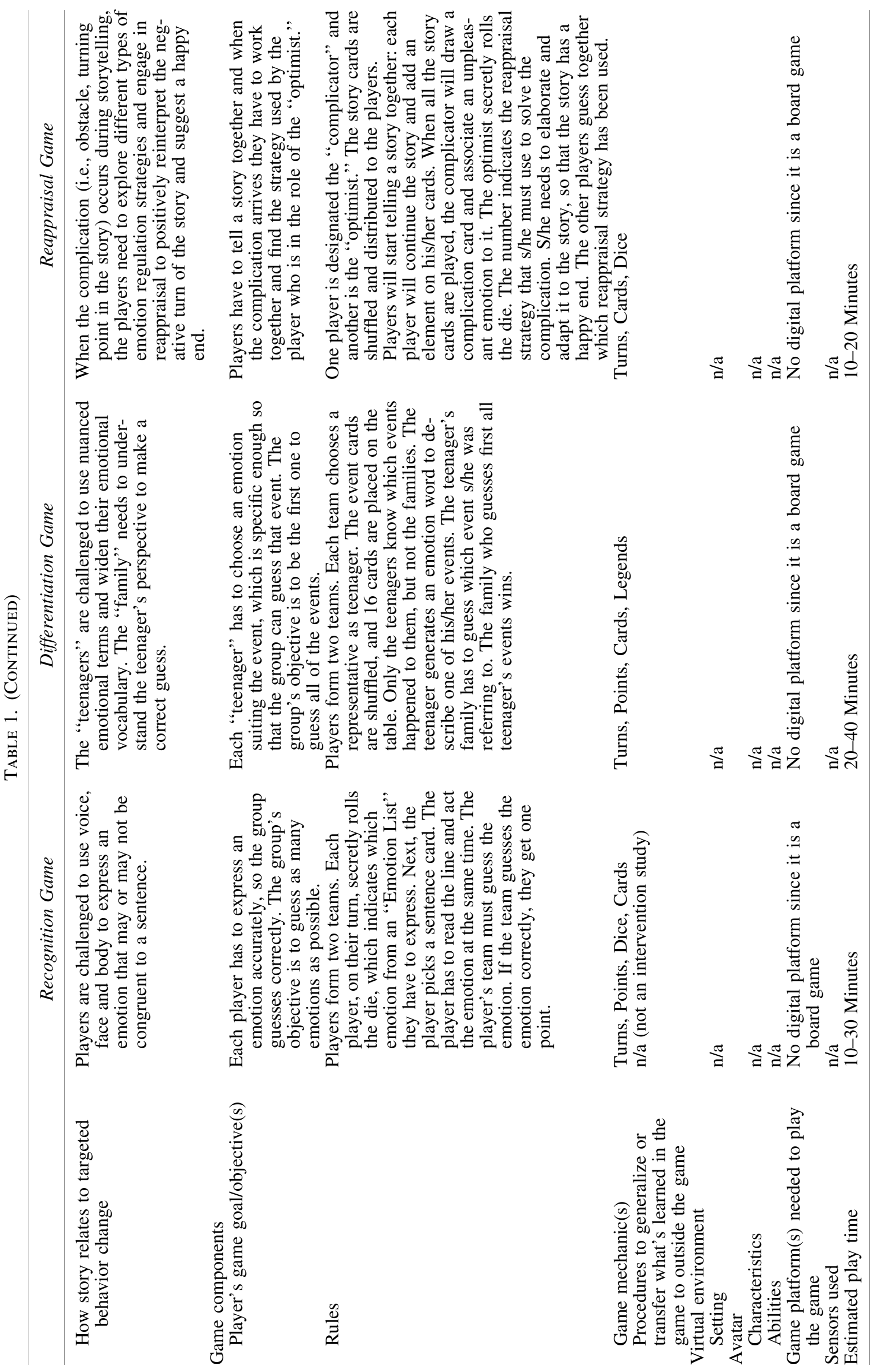


Table 2. Sample Characteristics

\begin{tabular}{|c|c|c|c|c|c|c|c|}
\hline \multirow[b]{2}{*}{ Variables } & \multicolumn{2}{|c|}{ Experimental } & \multicolumn{2}{|c|}{ Control } & \multicolumn{2}{|c|}{ Total } & \multirow[b]{2}{*}{ Statistics } \\
\hline & Mean & $S D$ & Mean & $S D$ & Mean & $S D$ & \\
\hline$N$ & 95 & & 79 & & 174 & & \\
\hline Age (years) & 9.91 & 1.21 & 10.10 & 1.45 & 9.99 & 1.32 & $t(159)=0.89, \mathrm{~ns}$ \\
\hline No. of siblings & 1.65 & 1.13 & 1.53 & 1.17 & 1.60 & 1.14 & $t(170)=-0.69, \mathrm{~ns}$ \\
\hline $\mathrm{SES}^{\mathrm{a}}$ & 3.09 & 0.82 & 3.06 & 0.83 & 3.08 & 0.82 & $t(157)=-0.30, \mathrm{~ns}$ \\
\hline GERT-S ${ }^{b}$ & 41.72 & 13.61 & 43.26 & 14.05 & 42.43 & 13.80 & $t(158)=0.38, \mathrm{~ns}$ \\
\hline EAQ-DIFF $^{\mathrm{c}}$ & 2.04 & 0.37 & 2.03 & 0.33 & 2.03 & 0.35 & $t(164)=-0.16, \mathrm{~ns}$ \\
\hline $\mathrm{ERQ}^{\mathrm{d}}$ & 4.31 & 1.19 & 4.26 & 1.46 & 4.28 & 1.32 & $t(158)=-0.25, \mathrm{~ns}$ \\
\hline
\end{tabular}

Statistics are independent samples $t$-tests, two-tailed.

a'Socioeconomic status: mean of parents' education and professional situation; $1=$ low to $4=$ high.

${ }^{\mathrm{b}}$ Emotion recognition as percentage of correct answers on the GERT.

${ }^{\mathrm{c}}$ Differentiation subscale from the EAQ; $1=$ not true to $3=$ true.

${ }^{\mathrm{d}}$ Habitual use of cognitive reappraisal from the ERQ; $1=$ strongly disagree to $7=$ strongly agree.

EAQ, Emotion Awareness Questionnaire; ERQ, Emotion Regulation Questionnaire; GERT-S, Geneva Emotion Recognition Test-Short; ns, non-significant; SD, standard deviation.

following predictors: emotion recognition and differentiation for the Recognition game; differentiation and cognitive reappraisal for the Differentiation game; and cognitive reappraisal for the Reappraisal game. In a separate set of regression analyses, the same variables were tested for the respective control games.

\section{Results}

\section{Descriptive analyses}

Independent samples $t$-tests revealed no significant differences on demographic variables and trait EC between experimental and control groups (Table 2).

\section{Comparison of EC board games with control games}

Figure 1 illustrates self-reported game experience for the Recognition Game and Mimtoo (Fig. 1A), the Differentiation Game and Codenames (Fig. 1B), and the Reappraisal Game and OUAT (Fig. 1C). All games produced patterns of high positive affect, low negative affect, medium to high flowimmersion and effort, and medium difficulty. MANOVAs showed no significant differences on the five dimensions between the Recognition Game and Mimtoo [Wilks' $\Lambda=0.95, F(5,156)=1.58, P=0.167]$, between the Differ- entiation Game and Codenames [Wilks' $\Lambda=0.95, F(5$, $150)=1.56, P=0.174]$, and between the Reappraisal Game and $O U A T$ [Wilks' $\Lambda=0.99, F(5,159)=0.30, P=0.911$ ].

\section{Associations between trait emotional competences and game experience}

For the Recognition Game, difficulty was negatively predicted by differentiation, but not by recognition. Effort was negatively predicted by recognition, but not by differentiation. For the Differentiation Game, difficulty was negatively predicted by both differentiation and reappraisal; effort was negatively predicted by differentiation only. For the Reappraisal Game, negative predictions from cognitive reappraisal on difficulty and effort were not confirmed (Table 3).

As for the control games, the separate multiple linear regressions showed no significant results regarding the associations between trait EC and game experience for Mimtoo or OUAT. However, reappraisal positively predicted effort for Codenames (Table 4).

\section{Discussion}

The first goal of the present study was to compare the EC board games with off-the-shelf games in an exploratory
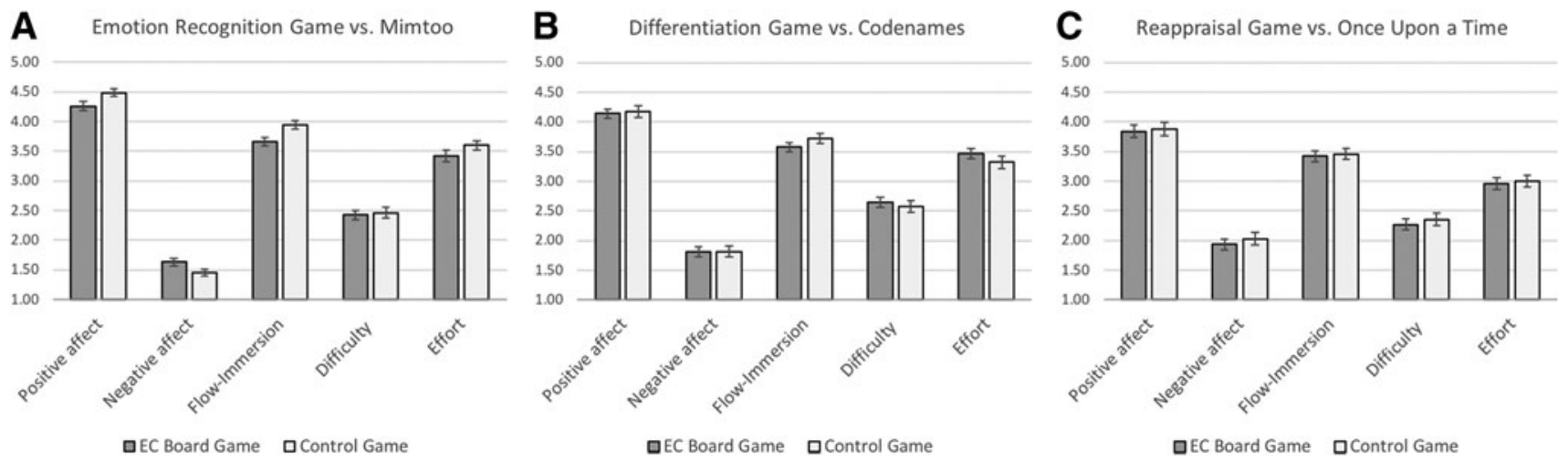

FIG. 1. The five dimensions of the game experience for EC Games (dark gray bars) compared to their respective control games (light gray bars). Error bars represent \pm 1 standard error. EC, emotional competences. 
Table 3. Linear Regression Results for Emotional Competences Games

\begin{tabular}{|c|c|c|c|c|c|c|}
\hline \multirow[b]{2}{*}{ Predictors } & \multicolumn{2}{|c|}{ Recognition Game } & \multicolumn{2}{|c|}{ Differentiation Game } & \multicolumn{2}{|c|}{ Reappraisal Game } \\
\hline & Difficulty & Effort & Difficulty & Effort & Difficulty & Effort \\
\hline $\begin{array}{l}\text { Recognition } b(\mathrm{SD}) \\
\text { Differentiation } b(\mathrm{SD})\end{array}$ & $\begin{array}{l}-1.01(0.57) \\
-0.39(0.17)^{\mathrm{b}}\end{array}$ & $\begin{array}{l}-1.54(0.75)^{\mathrm{a}} \\
-0.39(0.23)\end{array}$ & $-0.49(0.18)^{a}$ & $-0.59(0.19)^{\mathrm{a}}$ & & \\
\hline Reappraisal $b$ (SD) & & & $-0.18(0.07)^{\mathrm{a}}$ & $0.04(0.07)$ & $0.02(0.07)$ & $0.13(0.0$ \\
\hline$F(\mathrm{df})$ & $4.56(2,80)^{\mathrm{b}}$ & $4.09(2,80)^{\mathrm{b}}$ & $7.83(2,79)^{\mathrm{a}}$ & $4.83(2,79)^{\mathrm{b}}$ & $0.11(1,83)$ & $2.58(1,8$ \\
\hline$R^{2}$ change & 0.102 & 0.093 & 0.165 & 0.109 & 0.001 & 0.030 \\
\hline
\end{tabular}

Statistics: unstandardized coefficients $(b)$ with standard deviation (SD) for each predictor, Fisher's $F$ (df, degrees of freedom) and change of effect size $\left(R^{2}\right)$ for each linear regression.

${ }^{\mathrm{a}} P<0.01$.

${ }^{\mathrm{b}} P<0.05$

analysis. Results revealed that the game experience of children playing the EC board games was not significantly different to the one of children playing control games. Therefore, the EC board games seem to trigger a game experience comparable to the off-the-shelf games' patterns (e.g., high positive emotions and immersion) (Fig. 1), which could be interpreted as an indicator for the quality of the EC board games.

The second goal was to examine whether the EC targeted in each of the new games (recognition, differentiation, and reappraisal) were linked to the perceived game experience. We hypothesized that higher trait EC would be associated to lower perceived difficulty of the games and less effort invested in gameplay in the experimental group. Using linear regression analyses, we identified that certain EC traits were linked to difficulty and effort during game play as reported by the children.

For the Recognition Game, the hypothesis was confirmed: both emotion recognition and differentiation negatively predicted game experience (differentiation was linked to difficulty, recognition to effort). This suggests that being able to draw on a more differentiated emotional vocabulary and to map those labels on others' expressions helped the children to play the game, which was then perceived to be less difficult or to require less effort.

Game experience of the Differentiation Game was expected to vary with trait emotion differentiation and cognitive reappraisal. As expected, emotion differentiation skills were negatively linked to perceived difficulty and effort while playing the game. Therefore, a differentiated emotional vocabulary seems to benefit gameplay in this game. The habitual use of reappraisal was only negatively associated with difficulty. Thus, children who use reappraisal frequently seem to find the Differentiation Game less difficult. Given this result, we could assume that the game has the potential to challenge both differentiation and reappraisal skills. However, the link between reappraisal and effort is not yet clear and should be further investigated.

In the Reappraisal Game, the habitual use of reappraisal was not associated to difficulty and effort, contrary to our hypothesis. A possible explanation is the design of the game: the challenge to reappraise only occurs at the end of gameplay. For groups that constructed their stories very rapidly, members may have not been sufficiently invested in their stories to fully engage in reappraisal. We suggest future modifications to address this problem, for instance, by incorporating more complications that need to be reappraised throughout the story, facilitating the use of this EC. Another explanation might be that the game mostly requires the cognitive component of reappraisal. The game probably does not induce strong negative emotions needing reappraisal, so regulation of emotional arousal is only minimally required. Certain game mechanics, such as high-risk choices, time constraints, or unexpected negative consequences, have more potential to increase arousal in players and might be considered for future adaptations of this game.

Finally, we also explored the links between EC and game experience in the control games. No significant results were

Table 4. Linear Regression Results for Control Games

\begin{tabular}{|c|c|c|c|c|c|c|}
\hline \multirow[b]{2}{*}{ Predictors } & \multicolumn{2}{|c|}{ Mimtoo } & \multicolumn{2}{|c|}{ Codenames } & \multicolumn{2}{|c|}{ Once Upon A Time } \\
\hline & Difficulty & Effort & Difficulty & Effort & Difficulty & Effort \\
\hline Recognition $b$ (SD) & $-0.62(0.62)$ & $0.37(0.62)$ & & & & \\
\hline Differentiation $b$ (SD) & $-0.02(0.19)$ & $0.23(0.19)$ & $-0.16(0.22)$ & $-0.16(0.22)$ & & \\
\hline Reappraisal $b$ (SD) & & & $0.05(0.07)$ & $0.20(0.07)^{\mathrm{a}}$ & $0.10(0.07)$ & $0.10(0.07)$ \\
\hline$F(\mathrm{df})$ & $0.51(2,65)$ & $0.83(2,65)$ & $0.48(2,58)$ & $4.19(2,58)^{\mathrm{b}}$ & $1.89(1,68)$ & $2.14(1,6$ \\
\hline$R^{2}$ change & 0.015 & 0.025 & 0.016 & 0.126 & 0.027 & 0.031 \\
\hline
\end{tabular}

Statistics: unstandardized coefficients $(b)$ with standard deviation (SD) for each predictor, Fisher's $F$ (df, degrees of freedom) and change of effect size $\left(R^{2}\right)$ for each linear regression.

${ }^{\mathrm{a}} P<0.01$

${ }^{\mathrm{b}} P<0.05$ 
found for Mimtoo and OUAT. However, reappraisal was positively associated with effort for Codenames. Interestingly, this suggests that children with higher reappraisal skills seem to invest more effort in this game. One possible explanation is that Codenames might involve reappraisal skills since players may need to change their interpretation of a specific word (e.g., find multiple meanings of one word). Further investigation is required to identify the underlying mechanisms explaining this link.

To summarize, the present study shows that for two of the three EC board games (Recognition Game and Differentiation Game), children's trait EC were linked to difficulty and effort during gameplay. Therefore, we could speculate that these games might challenge the intended EC, which should be examined in future studies. The results also call for modifications of the games, for example, to better implement cognitive reappraisal in the Reappraisal Game.

\section{Limitations}

Despite these promising results, several limitations must be mentioned. First, the BGEQ was adapted from a questionnaire on digital games, but has not been validated in an independent sample with other measures and games beforehand. However, the BGEQ had satisfactory psychometric properties (Supplementary Data). Moreover, despite a good internal consistency, this is one of the first times when GERT-S was tested with children. ${ }^{65}$ Future studies should further assess the validity of both measures in children.

Another limitation is the reliance on self-reported game experience without more objective performance measures. In the current setup, individual performance was difficult to measure objectively since our games are based on group discussion and collective answers. Measures of individual behavior (e.g., number or accuracy of individual answers) might have an impact on group dynamics. However, we envision adapting the games in a way that individual performance could be tracked for future studies.

Furthermore, experimenters were not blind to the game they used. Although the participants were not informed about the existence of experimental and control conditions, we cannot rule out that they complied to experimental expectations.

In addition, only a single play session per game may not reveal strong associations between trait EC and game experience, since children must first learn the rules and familiarize themselves with the new game. Future studies should plan more sessions per game.

Notwithstanding these limitations, the strength of the study is the large and heterogeneous sample: children were recruited from different socioeconomic backgrounds and nationalities in public and private schools.

\section{Conclusions and Future Perspectives}

The present study provides first evidence of the potential of two newly developed EC board games to target and implement emotion recognition, differentiation and cognitive reappraisal. While a third game certainly needs further modifications and testing of the game experience (e.g., the reappraisal component should be applied throughout the story, not just at the end), the Recognition and the Differentiation Games could also benefit from adaptations according to qualitative feedback from the children, experimenters' ob- servations during the study, and the conclusions drawn from the results above. For example, children suggested a time limit for the Differentiation Game and an adaptation of its difficulty level.

In the future, modified versions of the EC board games should be rigorously tested within a longitudinal intervention study to investigate their potential to actually improve EC. Such a project should comprise several play sessions for each game and compare pre-, post-, and follow-up measures of EC between an experimental and an active control group. Assessing children's performance in the games would help to understand how children use their EC during gameplay. Also, the spontaneous play with the games after the intervention could be interesting to assess, since that could indicate if children perceive them as games, not only as playful educational material. ${ }^{40}$ Finally, one could explore possibilities to integrate the games into existing SEL programs. The games could be easily adapted for clinical settings, for example for children with developmental disorders with low EC. ${ }^{66-68}$

To conclude, this study is a first step in the long process of designing and testing quality board games to promote EC in children. Some encouraging results indicate that we are heading into the right direction, whereas some unexpected findings point to necessary modifications of the games. Future research is required to examine the potential of the board games to promote EC in intervention studies.

\section{Acknowledgments}

We thank many people who gave us constructive feedback on the games, including Jeremy Falger, Owen Harris, the children and teachers of the school "La Decouverte" in Geneva, Switzerland, as well as many colleagues who playtested the games with us. The authors thank all children, parents, and schools that participated in the study. We also thank Daniel Dukes for proofreading the article. Authors also thank Céline Horvath and Erika Mathez for their help in data collection.

\section{Authors' Contributions}

Principal investigators: A.C.S. and D.S.; responsible for the game design: A.C.S., A.L., L.D.A., and O.V.B.; development of study design: A.C.S., A.L., A.Z., and D.S.; data collection: A.Z., L.D.A., O.V.B.

\section{Author Disclosure Statement}

No competing financial interests exist for any of the authors of the study.

\section{Funding Information}

This research was supported by the National Center of Competence in Research (NCCR) Affective Sciences, financed by the Swiss National Science Foundation (SNSF; 51NF40104897), and hosted by the University of Geneva, and by the SNSF (PZ00P1_154937 and PP00P1_176722 for A.C.S.).

\section{Supplementary Material}

Supplementary Data

Supplementary Table S1

Supplementary Table S2 


\section{References}

1. Brackett MA, Rivers SE, Reyes MR, Salovey P. Enhancing academic performance and social and emotional competence with the RULER feeling words curriculum. Learn Individ Differ 2012; 22:218-224.

2. Durlak JA, Weissberg RP, Dymnicki AB, et al. The impact of enhancing students' social and emotional learning: A meta-analysis of school-based universal interventions. Child Dev 2011; 82:405-432.

3. Lyubomirsky S, King L, Diener E. The benefits of frequent positive affect: Does happiness lead to success? Psychol Bull 2005; 131:803-855.

4. Mega C, Ronconi L, De Beni R. What makes a good student? How emotions, self-regulated learning, and motivation contribute to academic Achievement. J Educ Psychol 2014; 106:121-131.

5. Hascher T, Edlinger H. Positive Emotionen und Wohlbefinden in der Schule-ein Überblick über Forschungszugänge und Erkenntnisse [Positive emotions and well-being in school-an overview of methods and results], Psychologie in Erziehung und Unterricht 2009; 56:105-122.

6. Shao K, Pekrun R, Nicholson L. Emotions in classroom language learning: What can we learn from achievement emotion research? System 2019; 86:102121.

7. Matsumoto D, Keltner D, Shiota MN, et al. Facial expressions of emotion. In: Lewis M, Haviland-Jones, JM, \& Barrett LF, eds., Handbook of emotions. New York: The Guilford Press 2008; 211-234.

8. Salovey P, Mayer JD. Emotional intelligence. Imagination, Cognition, and Personality 1990, 9:185-211.

9. Izard CE, Fine SE, Mostow AJ, et al. Emotion processes in normal and abnormal development and preventative intervention. Dev Psychopathol 2002; 14:761-787.

10. Fernandez KC, Jazaieri H, Gross JJ. Emotion regulation: A transdiagnostic perspective on a new RDoC domain. Cognit Ther Res 2016; 40:426-440.

11. Greenberg MT, Weissberg RP, O'Brien MU, et al. Enhancing school-based prevention and youth development through coordinated social, emotional, and academic learning. Am Psychol 2003; 58:466-474.

12. Weissberg RP, Goren P, Domitrovich C, Dusenbury L. CASEL Guide for Effective Social and Emotional Learning Programs: Preschool and Elementary School Edition. Chicago, IL: CASEL; 2013.

13. Durlak JA, Wells AM. Primary prevention mental health programs for children and adolescents: A meta-analytic review. Am J Community Psychol 1997; 25:115-152.

14. Zins JE, Elias MJ. Social and Emotional Learning: Promoting the Development of All Students, Journal of Educational and psychological consultation 2007, 17:2-3, 233-255.

15. Trull TJ, Lane SP, Koval P, Ebner-Priemer UW. Affective dynamics in psychopathology. Emot Rev 2015; 7:355-361.

16. Kashdan TB, Barrett LF, McKnight PE. Unpacking emotion differentiation: Transforming unpleasant experience by perceiving distinctions in negativity. Curr Dir Psychol Sci 2015; 24:10-16.

17. Smidt KE, Suvak MK. A brief, but nuanced, review of emotional granularity and emotion differentiation research. Curr Opin Psychol 2015; 3:48-51.

18. Tugade MM, Fredrickson BL, Feldman-Barrett L. Psychological resilience and positive emotional granilarity: Examining the benefits of positive emotions on coping and health. J Pers 2004; 72:1161-1191.
19. Quoidbach J, Berry EV, Hansenne M, Mikolajczak M. Positive emotion regulation and well-being: Comparing the impact of eight savoring and dampening strategies. Pers Individ Dif 2010; 49:368-373.

20. Zeman J, Cassano M, Perry-Parrish C, Stegall S. Emotion regulation in children and adolescents. J Dev Behav Pediatr 2006; 27:155-168.

21. Leppänen JM, Hietanen JK. Emotion recognition and social adjustment in school-aged girls and boys. Scand J Psychol 2001; 42:429-435.

22. Schlegel K, Fontaine JRJ, Scherer KR. The nomological network of emotion recognition ability: Evidence from the Geneva Emotion Recognition Test. Eur J Psychol Assess 2017; pp. 1-17.

23. Bajgar J, Ciarrochi J, Lane R, Deane FP. Development of the levels of emotional awareness scale for children (LEAS-C). Br J Dev Psychol 2005; 23:569-586.

24. Castro VL, Cheng Y, Halberstadt AG, Grühn D. EUReKA! A conceptual model of emotion understanding. Emot Rev 2016; 8:258-268.

25. Reschke PJ, Walle EA, Dukes D. Interpersonal development in infancy: The interconnectedness of emotion understanding and social cognition. Child Dev Perspect 2017; 11:178-183.

26. Barrett LF. Feelings or words? Understanding the content in self-report ratings of experienced emotion. J Pers Soc Psychol 2004; 87:266-281.

27. Barrett LF. Solving the emotion paradox: Categorization and the experience of emotion. Personal Soc Psychol Rev 2006; 10:20-46.

28. Barrett LF, Gross JJ, Christensen TC, Benvenuto M. Knowing what you're feeling and knowing what to do about it: Mapping the relation between emotion differentiation and emotion regulation. Cogn Emot 2001; 15:713724.

29. Keltner D, Locke KD, Aurain PC. The influence of attributions on the relevance of negative feelings to personal satisfaction. Personal Soc Psychol Bull 1993; 19:21-29.

30. Lahaye M, Luminet O, Van Broeck N, et al. Psychometric properties of the Emotion Awareness Questionnaire for children in a French-speaking population. J Pers Assess 2010; 92:317-326.

31. Sendzik L, Schäfer JÖ, Samson AC, et al. Emotional awareness in depressive and anxiety symptoms in youth: A meta-analytic review. J Youth Adolesc 2017; 46:687-700.

32. Gross JJ. The emerging field of emotion regulation: An integrative review. Rev Gen Psychol 1998; 2:271-299.

33. Aldao A, Nolen-Hoeksema S, Schweizer S. Emotionregulation strategies across psychopathology: A metaanalytic review. Clin Psychol Rev 2010; 30:217-237.

34. Schäfer JÖ, Naumann E, Holmes EA, et al. Emotion regulation strategies in depressive and anxiety symptoms in youth: A meta-analytic review. J Youth Adolesc 2017; 46: 261-276.

35. John OP, Gross JJ. Healthy and unhealthy emotion regulation: Personality processes, individual differences, and life span development. J Pers 2004; 72:1301-1333.

36. McRae K, Ciesielski B, Gross JJ. Unpacking cognitive reappraisal: Goals, tactics, and outcomes. Emotion 2012; $12: 250-255$.

37. Israelashvili J, Oosterwijk S, Sauter D, Fischer A. Knowing me, knowing you: Emotion differentiation in oneself is associated with recognition of others' emotions. Cogn Emot 2019; 33:1461-1471. 
38. Nicolopoulou A. Play, cognitive development, and the social world: Piaget, vygotsky, and beyond. Hum Dev 1993; 36:1-23.

39. Hassinger-Das B, Toub TS, Zosh JM, et al. More than just fun: a place for games in playful learning. Infanc y Aprendiz 2017; 40:191-218.

40. Hirsh-Pasek K, Golinkoff RM. Why play=learning. In: Tremblay RE, Barr RG, Peters RDeV, Boivin M, eds. Encyclopedia on Early Childhood Development. Montreal, Quebec: Centre of Excellence for Early Childhood Development 2008; pp. 1-7.

41. Hromek R, Roffey S. Promoting social and emotional learning with games. Simul Gaming 2009; 40:626-644.

42. Piaget J. Play, Dreams and Imitation in Childhood. London: Routledge and Kegan Paul Ltd; 1951.

43. Smith PK, Pellegrini, A. Leaning Through Play. In: Tremblay RE, Boivin M, Peters RDeV, eds. Smith PK, topic ed. Encyclopedia on Early Childhood Development [online]. Montreal, Quebec: Centre of Excellence for Early Childhood Development 2013; pp. 1-5.

44. Whitebread D, Verma M, Kuvalja M, Basilio M. The Importance of Play. Toy Industries of Europe (TIE); April 2012.

45. Ruben BD. Simulations, games, and experience-based learning: The quest for a new paradigm for teaching and learning. Simul Gaming 1999; 30:498-505.

46. Howard-Jones PA, Jay T, Mason A, Jones H. Gamification of learning deactivates the default mode network. Front Psychol 2016; 6:1-16.

47. Wohlwend K, Peppler K. All rigor and no play is no way to improve learning. Phi Delta Kappan 2015; 96:22-26.

48. Lillard AS, Lerner MD, Hopkins EJ, et al. The impact of pretend play on children's development: A review of the evidence. Psychol Bull 2013; 139:1-34.

49. Sprung M, Münch HM, Harris PL, et al. Children's emotion understanding: A meta-analysis of training studies. Dev Rev 2015; 37:41-65.

50. Lennon JL, Coombs DW. The utility of a board game for dengue haemorrhagic fever health education. Health Educ 2007; 107:290-306.

51. Verenikina I, Harris P, Lysaght P. Child's play: Computer games, theories of play and children's development. Young Child 2003:99-106.

52. Retalis S. Creating adaptive e-learning board games for school settings using the ELG environment. J Univers Comput Sci 2008; 14:2897-2908.

53. Ramani GB, Siegler RS, Hitti A. Taking it to the classroom: Number board games as a small group learning activity. J Educ Psychol 2012; 104:661-672.

54. Connolly TM, Boyle EA, MacArthur E, et al. A systematic literature review of empirical evidence on computer games and serious games. Comput Educ 2012; 59:661-686.
55. Sweetser P, Wyeth P. GameFlow: A Model for evaluating player enjoyment in games. Comput Entertain 2005; 3:1-24.

56. Bourgoin N. Mimtoo. Cocktail Games; 2012.

57. Chvàtil V. Codenames. Czech Games Edition; 2015.

58. Lambert R, Rilstone A, Wallis J. Once upon a time: The storytelling card game. Atlas Games; 1993.

59. Schlegel K, Scherer KR. Introducing a short version of the Geneva Emotion Recognition Test (GERT-S): Psychometric properties and construct validation. Behav Res Methods 2016; 48:1383-1392.

60. Schlegel K, Grandjean D, Scherer KR. Introducing the Geneva Emotion Recognition Test: An example of Raschbased test development. Psychol Assess 2014; 26:666672.

61. Rieffe C, Oosterveld P, Terwogt MM. An alexithymia questionnaire for children: Factorial and concurrent validation results. Pers Individ Dif 2006; 40:123-133.

62. Gross JJ, John OP. Individual differences in two emotion regulation processes: Implications for affect, relationships, and well-being. J Pers Soc Psychol 2003; 85: 348-362.

63. Gullone E, Taffe J. The Emotion Regulation Questionnaire for Children and Adolescents (ERQ-CA): A psychometric evaluation. Psychol Assess 2012; 24:409-417.

64. IJsselsteijn WA, de Kort YAW, Poels K. The Game Experience Questionnaire. Eindhoven: Technische Universiteit Eindhoven 2013; pp. 1-9.

65. Wang Y, Hawk ST, Tang Y, Schlegel K. Characteristics of emotion recognition ability among primary school children: Relationships with peer status and friendship quality. Child Indicators Res 2018; 12:1369-1388.

66. Cai RY, Richdale AL, Dissanayake C, et al. Emotion regulation in autism: Reappraisal and suppression interactions. Autism 2018; 23:737-749.

67. Mazefsky CA, White SW. Emotion regulation. Concepts \& practice in autism spectrum disorder. Child Adolesc Psychiatr Clin N Am 2014; 23:15-24.

68. Samson AC, Huber O, Gross JJ. Emotion regulation in Asperger's syndrome and high-functioning autism. Emotion 2012; 12:659-665.

\author{
Address correspondence to: \\ Andrea C. Samson \\ Institute of Special Education \\ University of Fribourg \\ Rue St. Pierre Canisius 21 \\ 1700 Fribourg \\ Switzerland
}

E-mail: andrea.c.samson@gmail.com 